\title{
Physical and Mental Fatigue in Subjects Recovered from COVID-19 Infection: A Case-Control Study
}

\author{
Rehab Elanwar' \\ Mona Hussein $\mathbb{D}^{2}$ \\ Rehab Magdy ${ }^{3}$ \\ Ragaey A Eid (iD) ${ }^{4}$ \\ Ahmed Yassien ${ }^{5}$ \\ Ahmed S Abdelsattar ${ }^{6}$ \\ Laila A Alsharaway (D) $^{7}$ \\ Wael Fathy $\mathbb{D}^{8}$ \\ Amr Hassan (D) 9 \\ Yasmine S Kamal ${ }^{9,10}$ \\ 'Clinical Neurophysiology, Neurodiagnostic \\ Research Center, Beni-Suef University, Beni- \\ Suef, Egypt; ${ }^{2}$ Department of Neurology, \\ Beni-Suef University, Beni-Suef, Egypt; \\ ${ }^{3}$ Department of Neurology, Cairo \\ University, Cairo, Egypt; ${ }^{4}$ Department of \\ Tropical Medicine, Beni-Suef University, \\ Beni-Suef, Egypt; ${ }^{5}$ Department of Critical \\ Care Medicine, Beni-Suef University, Beni- \\ Suef, Egypt; ${ }^{6}$ Department of Internal \\ Medicine, Beni-Suef University, Beni-Suef, \\ Egypt; ${ }^{7}$ Department of Chest Diseases, \\ Beni-Suef University, Beni-Suef, Egypt; \\ ${ }^{8}$ Department of Anaesthesia, Surgical ICU \\ and Pain Management, Beni-SuefUniversity, \\ Beni-Suef, Egypt; ${ }^{9}$ Department of \\ Neurology, Kasr Al Ainy Hospital, Faculty of \\ Medicine, Cairo University, Cairo, Egypt; \\ ${ }^{10}$ Department of Neurology, Rashid \\ Hospital, Dubai, United Arab Emirates
}

Purpose: Much effort has been directed toward studying COVID-19 symptoms; however, the post-COVID-19 phase remains mysterious. The aim of this work was to conduct a clinical and neurophysiological evaluation of physical and mental fatigue in COVID-19 long-haulers and to study whether markers of COVID-19 severity are able to predict the likelihood of developing postinfectious fatigue syndrome (PIFS) in such patients.

Patients and Methods: This case-control study was conducted on 46 COVID-19 longhaulers who met the criteria for PIFS and 46 recovered COVID-19 subjects without any residuals. Clinical assessment of fatigue was done using a fatigue questionnaire. Repetitive nerve stimulation and single-fiber electromyography were done after excluding neuropathy and myopathy.

Results: The median value for physical fatigue was 4 (IQR 2-7), while that for mental fatigue was 2 (IQR 0-3). Each day's increase in the period of COVID-19 illness increased the odds of PIFS in COVID-19 long-haulers 1.104-fold, and each unit increase in ferritin increased the odds of PIFS 1.006-fold. A significant decrement in at least one muscle was observed in $50 \%$ of patients. Patients with PIFS had significantly higher mean consecutive difference $(\mathrm{MCD})$ in the extensor digitorum communis than the control group. There were statistically significant positive correlations between MCD values and physical, mental, and total fatigue scores.

Conclusion: Higher ferritin levels and prolonged COVID-19 infection were independent predictors of PIFS in COVID-19 long-haulers. There was electrophysiological evidence of abnormalities in the peripheral portion of the motor unit in COVID-19 long-haulers with PIFS.

Keywords: COVID-19, fatigue, COVID-19 long-haulers, single-fiber EMG, ferritin

\section{Introduction}

Since the beginning of the SARS-CoV2 pandemic, health-care professionals have been challenged by its variable clinical manifestations. Much effort has been directed toward studying the prevalence and patterning of COVID-19 symptoms. ${ }^{1}$ Nevertheless, the post-COVID phase is still worth exploring.

SARS-CoV2 was recently reported to be a potential trigger for postinfectious fatigue syndrome (PIFS). ${ }^{2}$ PIFS refers to severe, disabling, and persistent/recurrent physical and/or mental fatigue following infectious triggers, such as viruses, bacteria, and parasites. ${ }^{3}$ The terms myalgic encephalomyelitis (ME), chronic FS (CFS) and postviral FS (PVFS) are also used to describe this condition. ${ }^{4}$
Correspondence: Mona Hussein

Department of Neurology, Beni-Suef

University, Salah Salem Street, Beni-Suef,

$6255 \mathrm{I}$, Egypt

Tel +20-10-0513-1318

Email mona.neuro@yahoo.com 
Health-care professionals should be aware of such disorder because it greatly affects functional status and quality of life of the patients comparably with other diseases, such as depression, cancer, multiple sclerosis, rheumatoid arthritis, HIV, heart disease, and end-stage renal diseases ${ }^{5-7}$ The economic impact of PIFS on society is also substantial, because this disorder may result in decreased productivity and loss of employment. ${ }^{8}$ As such, rehabilitation care for COVID-19 survivors with PIFS must be focused on and delivered by multidisciplinary teams. This may decrease the consequences of fatigue and improve functional outcomes in activities of daily living. ${ }^{9-13}$

The etiology of PIFS remains elusive; however, a number of mechanisms have been suggested, such as immunodysfunction, neuroinflammation, enhanced oxidative stress, mitochondrial dysfunction, neuroendocrine disorder, and hereditary predisposition. ${ }^{4}$ The hallmarks of PIFS include easy fatigability, postexertional malaise, pains, sleep abnormalities, and autonomic dysfunction that must be present or recurrent for at least 6 months. The patient's functional level must decrease by more than $50 \%$ compared with preillness levels. ${ }^{3,14}$ No cure currently exists; therefore, treatment of PIFS aims mainly at alleviating symptoms and improving functional status. $^{15}$

Electrophysiological studies remain an extension of clinical assessment and help in accurate localization, thus providing guidance for proper management, especially when dealing with subjective complaints. ${ }^{16}$ Several electrophysiological studies have been done to localize sites of abnormality in motor units in patients with CFS. Reduced recruitment of voluntary motor units and jitter abnormalities were reported in some patients. $^{17-19}$

\section{Aim of This Work}

This study aimed to evaluate physical and mental fatigue and their neurophysiological correlate in subjects recovered from COVID-19 andto study whether clinical, laboratory, and radiological markers of COVID-19 severity cand predict the likelihood of developing PIFS in COVID-19 long-haulers.

\section{Patients and Methods Design and Participants}

This case-control study was conducted between November 1, 2020 and February 1, 2021. Study subjects were COVID-19 long-haulers who were diagnosed as having PIFS according to the US National Academies of Sciences, Engineering, and Medicine, ${ }^{20}$ and another sample of age- and sex-matched volunteers who had recovered from COVID-19 infection without any residuals. In order to fulfill the definition of PIFS, ${ }^{20}$ patients had to have persistent fatigue for at least 6 months after recovery. The patient group was recruited from the COVID-19 Clinic, Beni-Suef University Hospital. Health workers who had recovered from COVID-19 without any residuals were recruited as a control group.

According to the World Health Organization, ${ }^{21}$ recovery from COVID-19 infection is defined as improvement in all symptoms of COVID-19, absence of fever for 3 consecutive daysand negative results for two consecutive SARS-CoV2 tests at a 24-hour interval.

We excluded patients with a history of CFS preceding the onset of COVID-19, any medical disorder known to be associated with fatigue (eg, cardiac disorders, hypothyroidism, malignancy), any central or peripheral neurological disorder, and depressive disorders according to the Diagnostic and Statistical Manual of Mental Disorders fifth edition. ${ }^{22}$

\section{Measures}

Data on duration of COVID-19 infection, including symptomatology, steroid intake, initial laboratory markers (serum CRP, ferritin, and neutrophil-lymphocyte ratio), and results of chest imaging, were obtained from BeniSuef University Hospital medical records. The COVID-19 Reporting and Data System (CO-RADS) ${ }^{23}$ was used for radiological grading of pulmonary involvement.

All participants underwent face-to-face interviews for data collection, including demographics, smoking status, and body-mass index (BMI), as well as detailed general and neurological examinations.

At tienrollment, fatigue was assessed using a fatigue questionnaire. ${ }^{24}$ This was an eleven-item scale to assess physical and mental fatigue. Items 1-7 represent physical fatigue, while items 8-11 represent mental fatigue. Each item was scored using a bimodal response system: better than usual or no more than usual $=0$, worse than usual or much worse than usual $=1$.

Patients were also assessed for any other associated long COVID-19 manifestations, such as musculoskeletal pains, insomnia, dizziness, sore throat, and tender lymph nodes. 


\section{Neurophysiological Assessment}

Neurophysiological assessment was carried out for both groups at the Neurodiagnostic Research Center, Beni-Suef University using a Nihon Kohden apparatus. Motor and sensory nerve-conduction studies were done for the upper limbs (both ulnar nerves and left median nerves) and the lower limbs (both common peroneal nerves and right tibial nerve) to exclude any neuropathy. Electromyography (EMG) examinations of distal and proximal muscles were carried out to exclude any myopathy.

Slow $(3 \mathrm{~Hz})$ repetitive nerve stimulation (RNS) was performed for the ulnar and spinal accessory nerves while recording the abductor digiti minimi (ADM) and trapezius muscles, respectively, using surface electrodes at 1, 2, 3, and 4 minutes. RNS is positive when there is a decrement in compound muscle action potential amplitude and/or area $>10 \%$ between the first and fourth responses. ${ }^{25}$

Volitional single-fiber EMG (SFEMG) was carried out using a concentric facial needle. The band pass was 1-10 $\mathrm{kHz}$ (values of low- and high-frequency filters, respectively). Patients were asked to contract the muscle minimally and maintain this contraction. Four insertions were made to record 10-20 pairs of single muscle fibers. The needle was moved until locating a single muscle-fiber potential of amplitude $>200 \mu \mathrm{V}$ and rise time $<300 \mu$ s. The needle was then moved slightly to get a second potential that was timelocked to the first potential, denoting that it was from the same motor unit. Multiple consecutive firings of musclefiber action-potential were then recorded. By recording 50 100 subsequent potentials, the mean consecutive difference (MCD), a measure of jitter, was taken. Mean MCD was taken by repeating the procedure until collecting an adequate number of single-fiber pairs. SFEMG data (mean MCD and percentage of blocking) were measured from the extensor digitorum communis (EDC) muscle. ${ }^{26}$

\section{Sampling}

Because our study was the first study to use SFEMG for assessment of post-COVID fatigue, we calculated the sample size based on the results of a pilot study we performed before starting our study. The sample-size calculation was done using G*Power 3.1.9.2. The probability of type I error $(\alpha)$ was $5 \%$, effect size 0.761 , noncentrality parameter $\lambda=3.65$, critical $t=1.987$, and $d f=90$. A total sample of 46 patients in each group was required to achieve statistical power $(1-\beta)$ of $95 \%$.

\section{Ethics Statement}

Written informed consent was obtained from all participants. Ethics approval for this study was obtained from the research-ethics committee of Beni-Suef University (FMBSUREC/03012021/Hussein). The study was performed in accordance with the Declaration of Helsinki.

\section{Statistical Analysis}

SPSS 25 was used to analyze the data. The KolmogorovSmirnov test was used to test data normality. Categorical variables, ie, sex, smoking status, COVID and post-COVID symptoms, steroid intake, CO-RADS staging, and occurrence of decremental responses are expressed as numbers and percentages. Abnormally distributed quantitative variables, such as age, BMI, duration of illness, laboratory markers, and MCD, are expressed as medians and IQRs. Normally distributed quantitative variables, eg, percentage of decremental response, are expressed as means \pm SD. For comparisons between the fatigue and nonfatigue group on categorical variables, Chi square tests were used, whereas the Mann-Whitney $U$ test was used for quantitative abnormally distributed variables. Correlations between fatigue scores and MCD were assessed using the Spearman correlation test. Stepwise binary logistic regression was used to identify predictors of occurrence of PIFS after being adjusted for their potential mutual confounding effect. $P \leq 0.05$ was considered statistically significant. All tests were two-tailed.

\section{Results}

This was a case-control study that was conducted on 46 patients with PIFS (fatigue group) and 46 recovered COVID-19 subjects without fatigue (control group). The two groups were matched for age and sex $(P=0.063$ and 0.075 respectively).

Clinical assessment of fatigue in patients with PIFS using the fatigue questionnaire revealed that median values for physical fatigue, mental fatigue, total fatigue scores, were 4,2 , and 6 , respectively. In sum, 36 patients (78.3\%) had post-COVID musculoskeletal pain, 31 (67.4\%) orthostatic intolerance, $30(65.2 \%)$ insomnia, 12 (26.1\%) sore throat, and five (10.9\%) tender lymph nodes (Table 1 ).

\section{Clinical, Laboratory, and Radiological Parameters of COVID-19 Infection in Relation to Occurrence of PIFS}

On comparing the clinical, laboratory, and radiological parameters between the two groups, we found that patients with 
Table I Assessment of fatigue and other associated postCOVID-19 symptoms in patients with PIFS

\begin{tabular}{|c|c|c|c|}
\hline & & & $\begin{array}{l}\text { Fatigue } \\
\text { group } \\
(n=46)\end{array}$ \\
\hline \multirow{3}{*}{$\begin{array}{l}\text { Fatigue } \\
\text { questionnaire }\end{array}$} & \multicolumn{2}{|c|}{ Physical, median (IQR) } & $4(2-7)$ \\
\hline & \multicolumn{2}{|c|}{ Mental, median (IQR) } & $2(0-3)$ \\
\hline & \multicolumn{2}{|c|}{ Total, median (IQR) } & $6(3-9)$ \\
\hline \multirow{10}{*}{$\begin{array}{l}\text { Associated post- } \\
\text { COVID symptoms }\end{array}$} & \multirow{2}{*}{$\begin{array}{l}\text { Musculoskeletal } \\
\text { pain }\end{array}$} & Yes, n (\%) & $36(78.3 \%)$ \\
\hline & & No, n (\%) & $10(21.7 \%)$ \\
\hline & \multirow{2}{*}{$\begin{array}{l}\text { Orthostatic } \\
\text { intolerance }\end{array}$} & Yes, n (\%) & 31 (67.4\%) \\
\hline & & No, n (\%) & $15(32.6 \%)$ \\
\hline & \multirow[t]{2}{*}{ Insomnia } & Yes, n (\%) & $30(65.2 \%)$ \\
\hline & & No, n (\%) & $16(34.8 \%)$ \\
\hline & \multirow[t]{2}{*}{ Sore throat } & Yes, n (\%) & $12(26.1 \%)$ \\
\hline & & No, n (\%) & $34(73.9 \%)$ \\
\hline & \multirow[t]{2}{*}{ Tender LNs } & Yes, n (\%) & 5 (10.9\%) \\
\hline & & No, n (\%) & 41 (89.1\%) \\
\hline
\end{tabular}

Abbreviation: LNs, lymph nodes.

PIFS had significantly longer disease duration than controls $(P<0.001)$. The frequency of fever, respiratory manifestations, gastrointestinal tract symptoms, fatigue, and musculoskeletal pain were significantly higher in patients with PIFS ( $P=0.024,<0.001,0.001,0.005$, and $<0.001$, respectively). Frequency of steroid intake was significantly higher in patients with PIFS than controls $(P<0.001)$. Radiological findings for COVID-19 were significantly worse in patients with PIFS than controls $(P<0.001)$. Patients with PIFS had significantly higher CRP and ferritin levels than controls $(P=0.014$ and $<0.001$, respectively; Table 2$)$.

\section{Predictors of PIFS in COVID-19 Long-Haulers}

Stepwise binary logistic regression was done to identify predictors of PIFS. Duration of COVID-19 illness, fatigue, musculoskeletal pain, CO-RADS, CRP, and ferritin during the period of COVID-19 illness were used as the independent variables.

Only duration of COVID-19 illness and serum ferritin were retained as independent predictors occurrence of PIFS. Each day's increase in period of COVID-19 illness increased the odds of PIFS 1.104-fold and each unit increase in ferritin increased the odds of PIFS 1.006-fold (Table 3).

\section{Neurophysiological Assessment}

A significant decrement in at least one muscle was observed in 23 patients in the fatigue group (50\%). Mean values for decremental response were $11.8 \% \pm 0.837 \%$ in ADM and $11.5 \% \pm 0.648 \%$ in trapezius muscles. Patients with PIFS had significantly higher MCD in the EDC than controls $(P<0.001$, Table 4$)$. None of our patients showed blocking.

There were statistically significant positive correlations between MCD in the EDC and physical, mental, and total fatigue scores $(P=0.003,0.029$, and $<0.001$, respectively; Table 5, Figure 1).

\section{Discussion}

Fatigue is considered one of the most common complaints in COVID-19 patients. It has been found to be a presenting symptom in $44 \%-69.6 \%$ of patients infected with COVID19. ${ }^{27}$ The rates of post-COVID fatigue have been reported to be much higher than those previously reported following $\mathrm{Q}$ fever Epstein-Barr virus and Ross River virus. ${ }^{28}$ Nevertheless, a recent Iranian study reported that the prevalence of CFS among patients with COVID-19 was similar to that in the general population. ${ }^{29}$

Many researchers believe that the abnormal amplified immunoresponse triggered by a specific pathogen may have a significant role in the pathophysiology of PIFS. They have deemed the PIFS a failure state to "downregulate" the immune system, where inflammatory cytokines that are primarily released to attack viral agents invade dorsal root ganglia and muscles. This in turn promotes fatigue, a principal symptom of CFS and pain. ${ }^{30,31}$

For that purpose, markers of infection severity were investigated in this study as possible risk factors of PIFS. We found that patients with PIFS had significantly longer disease duration, higher levels of CRP and ferritin, and higher CORADS grading than the control group. However, only higher levels of ferritin and longer infection were found to be independent predictors of PIFS in recovered COVID-19 subjects.

Our results were in agreement with a previous study that revealed that PIFS was predicted principally by severity of infection, regardless of the causative viral pathogen. $^{32}$ On the other hand, Townsend and Dyer ${ }^{28}$ reported that post-COVID fatigue was not correlated with initial disease severity. 
Table 2 Demographics, clinical, radiological, and laboratory characteristics of the study population

\begin{tabular}{|c|c|c|c|c|c|}
\hline & & & \multicolumn{2}{|c|}{ Recovered COVID- 19 subjects $(n=92)$} & \multirow[t]{2}{*}{$\mathbf{P}$} \\
\hline & & & $\begin{array}{l}\text { Fatigue group } \\
\qquad(n=46)\end{array}$ & $\begin{array}{l}\text { Nonfatigue group } \\
\qquad(n=46)\end{array}$ & \\
\hline \multicolumn{3}{|l|}{ Age (years), median (IQR) } & $54.5(45.75-62)$ & $51(37-58)$ & 0.063 \\
\hline \multirow[t]{2}{*}{ Sex } & \multicolumn{2}{|l|}{ Male, n (\%) } & II (23.9\%) & 19 (4I.3\%) & \multirow[t]{2}{*}{0.075} \\
\hline & Female, n (\%) & & $35(76.1 \%)$ & 27 (58.7\%) & \\
\hline \multirow[t]{2}{*}{ Smoking } & Yes, n (\%) & & $2(4.3 \%)$ & $4(8.7 \%)$ & \multirow[t]{2}{*}{0.398} \\
\hline & No, n (\%) & & 44 (95.7\%) & 42 (91.3\%) & \\
\hline \multicolumn{3}{|l|}{ BMI, median (IQR) } & $28.04(25.07-31.68)$ & $29.22(27-32.4)$ & 0.656 \\
\hline \multicolumn{3}{|c|}{ Duration of illness (days), Median (IQR) } & $23(14-45)$ & $14(11-19.5)$ & $<0.001 *$ \\
\hline \multirow{12}{*}{$\begin{array}{l}\text { Symptoms during COVID-19 } \\
\text { infection }\end{array}$} & \multirow[t]{2}{*}{ Fever } & Yes, n (\%) & $44(95.7 \%)$ & 37 (80.4\%) & \multirow[t]{2}{*}{$0.024 *$} \\
\hline & & No, n (\%) & $2(4.3 \%)$ & $9(19.6 \%)$ & \\
\hline & \multirow{2}{*}{$\begin{array}{l}\text { Respiratory } \\
\text { manifestations }\end{array}$} & Yes, n (\%) & $4 \mathrm{l}(89.1 \%)$ & $18(39.1 \%)$ & \multirow[t]{2}{*}{$<0.00 I^{*}$} \\
\hline & & No, n (\%) & $5(10.9 \%)$ & $28(60.9 \%)$ & \\
\hline & \multirow[t]{2}{*}{ GIT symptoms } & Yes, n (\%) & $29(63 \%)$ & 13 (28.3\%) & \multirow[t]{2}{*}{$0.001 *$} \\
\hline & & No, n (\%) & 17 (37\%) & 33 (7I.7\%) & \\
\hline & \multirow[t]{2}{*}{ Headache } & Yes, n (\%) & 39 (84.8\%) & 33 (7I.7\%) & \multirow[t]{2}{*}{0.129} \\
\hline & & No, n (\%) & 7 (15.2\%) & $13(28.3 \%)$ & \\
\hline & \multirow[t]{2}{*}{ Fatigue } & Yes, n (\%) & 42 (91.3\%) & 31 (67.4\%) & \multirow[t]{2}{*}{$0.005^{*}$} \\
\hline & & No, n (\%) & $4(8.7 \%)$ & 15 (32.6\%) & \\
\hline & \multirow[t]{2}{*}{ Musculoskeletal pain } & Yes, n (\%) & $36(78.3 \%)$ & $13(28.3 \%)$ & \multirow[t]{2}{*}{$<0.001 *$} \\
\hline & & No, n (\%) & $10(21.7 \%)$ & 33 (7I.7\%) & \\
\hline \multirow[t]{2}{*}{ Steroid intake } & \multicolumn{2}{|l|}{ Yes, n (\%) } & 32 (69.6\%) & 15 (32.6\%) & \multirow[t]{2}{*}{$<0.001 *$} \\
\hline & No, n (\%) & & 14 (30.4\%) & 31 (67.4\%) & \\
\hline \multirow[t]{5}{*}{ CO-RADS staging } & I, n (\%) & & $3(6.5 \%)$ & $5(10.9 \%)$ & \multirow[t]{5}{*}{$<0.001 *$} \\
\hline & II, n (\%) & & 0 & $5(10.9 \%)$ & \\
\hline & III, n (\%) & & $5(10.9 \%)$ & $25(54.3 \%)$ & \\
\hline & IV, n (\%) & & II (23.9\%) & $2(4.3 \%)$ & \\
\hline & V, n (\%) & & 27 (58.7\%) & $9(19.6 \%)$ & \\
\hline \multirow[t]{3}{*}{ Laboratory workup } & \multicolumn{2}{|l|}{ NLR, median (IQR) } & $3.053(2.054-4.53)$ & $2.67(1.615-4.55)$ & 0.768 \\
\hline & \multicolumn{2}{|c|}{ CRP (mg/L), median (IQR) } & $25.5(12-92)$ & $24(12-38)$ & $0.014^{*}$ \\
\hline & Ferritin $(\mathrm{ng} / \mathrm{mL})$, med & QR) & $406(297.5-535)$ & $124(79-236)$ & $<0.00 I^{*}$ \\
\hline
\end{tabular}

Note: $* P \leq 0.05$ is considered significant.

Abbreviations: BMI, body mass index; CO-RADS, COVID-19 Reporting and Data System; GIT, gastrointestinal tract; NLR, neutrophil:lymphocyte ratio. 
Table 3 Stepwise logistic regression to detect predictors of PIFS

\begin{tabular}{|l|c|c|c|c|c|c|}
\hline & $\beta$ & Wald Chi & \multirow{2}{*}{ Odds ratio } & \multicolumn{2}{|c|}{$95 \%$ CI } \\
\cline { 3 - 7 } & & square & & & Lower & Upper \\
\hline Duration of illness, days & 0.099 & 6.109 & $0.013^{*}$ & 1.104 & 1.021 & 1.195 \\
\hline Ferritin $(\mathrm{ng} / \mathrm{mL})$ & 0.006 & 7.377 & $0.007^{*}$ & 1.006 & 1.002 & 1.010 \\
\hline Constant & -3.324 & 13.686 & 0 & 0.036 & & \\
\hline
\end{tabular}

Notes: Nagelkerke $R^{2}=0.523$; dependent variable - occurrence of PIFS; ${ }^{\mathrm{P}} \leq 0.05$ is considered significant.

The important point to clarify is that a significantly higher proportion of patients with PIFS were using steroids during the period of COVID-19 illness than the control group. This does not actually dampen the fact that immunodysfunction is a potential mechanism for PIFS. The possibility remains that steroid use primarily indicates a patient's poor clinical condition.

It should be noted that the aforementioned mechanism cannot alone elucidate the occurrence of CFS. There must be another central mechanism that underpins mental fatigue. Mental fatigue in CFS may be related to impaired regulation of global and regional cerebral blood flow, particularly during challenging mental tasks. ${ }^{33,34}$

It is well known that decremental responses in RNS are not conclusive for neuromuscular junction disorders, but can sometimes be seen in disorders that affect

Table 4 Neurophysiological findings in patients with and without PIFS

\begin{tabular}{|c|c|c|c|c|}
\hline & & \multicolumn{2}{|c|}{$\begin{array}{l}\text { Recovered COVID-19 } \\
\text { subjects }(n=92)\end{array}$} & \multirow[t]{2}{*}{$P$} \\
\hline & & $\begin{array}{l}\text { Fatigue } \\
\text { group } \\
(n=46)\end{array}$ & $\begin{array}{c}\text { Nonfatigue } \\
\text { group } \\
(n=46)\end{array}$ & \\
\hline \multicolumn{2}{|c|}{$\begin{array}{l}\text { MCD for EDC, median } \\
(\mathrm{IQR})\end{array}$} & $\begin{array}{c}40.7 \\
(36.70- \\
44.8)\end{array}$ & $\begin{array}{c}33.6(28.20- \\
36.48)\end{array}$ & $<0.001 *$ \\
\hline \multirow{2}{*}{$\begin{array}{l}\text { Decremental } \\
\text { response in } \\
\text { ADM }\end{array}$} & Yes, n (\%) & $6(13.0 \%)$ & 0 & \multirow[t]{2}{*}{$0.011^{*}$} \\
\hline & No, n (\%) & $\begin{array}{c}40 \\
(87.0 \%)\end{array}$ & 46 (100\%) & \\
\hline \multirow{2}{*}{$\begin{array}{l}\text { Decremental } \\
\text { response in } \\
\text { trapezius }\end{array}$} & Yes, n (\%) & $\begin{array}{c}20 \\
(43.5 \%)\end{array}$ & 0 & \multirow[t]{2}{*}{$<0.001 *$} \\
\hline & No, n (\%) & $\begin{array}{c}26 \\
(56.5 \%)\end{array}$ & 46 (100\%) & \\
\hline
\end{tabular}

Note: $* P \leq 0.05$ is considered significant.

Abbreviations: ADM, abductor digiti minimi; EDC, extensor digitorum communis; $M C D$, mean consecutive difference. peripheral nerve, muscle, or even anterior horn cells. ${ }^{35,36}$ However, the low rate of decremental response $(11 \%-13 \%)$ in our patients does not negate any of these possibilities. $^{36,37}$

SFEMG may provide a more accurate evaluation of the neuromuscular junction than RNS and thus may provide a better determination of the true condition of neuromuscular status. In this study, the fatigue group had significantly higher MCD than the control group, and none showed blocking. These results are in line with published data on PVFS caused by other viruses. ${ }^{17-19}$ Abnormal jitter points to a disturbance in the peripheral part of the motor unit, in either the terminal axon branches, the motor end plate, or the muscle fiber. ${ }^{26,38}$ However, we cannot determine a definite locale because fiber density cannot be reliably assessed using concentric needles. ${ }^{39}$

The disturbance in the muscle fiber of patients with PVFS was documented at pathological base. Behan et $\mathrm{al}^{40}$ were the first to examine muscle biopsies obtained from patients with PVFS, and found varying atrophy of type II fibers, with evident mitochondrial degeneration. After that, successive studies proved that mitochondrial dysfunction plays a fundamental role in the pathophysiology of PVFS..$^{41,42}$

Many researchers believe that rehabilitation of postCOVID patients is crucial for recovering from fatigue and improving functional status. It is also mandatory to manage residual post-COVID deficits of these patients, even after their discharge, through telerehabilitation. ${ }^{9,12}$

Table 5 Correlation between scores on fatigue questionnaire and MCD for EDC in patients with PIFS

\begin{tabular}{|c|c|c|c|c|}
\hline \multirow{2}{*}{} & \multicolumn{2}{|c|}{ Physical fatigue score } & \multicolumn{2}{c|}{ Mental fatigue score } \\
\cline { 2 - 5 } & $\boldsymbol{r}$ & $\boldsymbol{P}$ & $\boldsymbol{r}$ & $\boldsymbol{P}$ \\
\hline MCD for EDC & 0.425 & $0.003 *$ & 0.321 & $0.029 *$ \\
\hline
\end{tabular}

Note: $* P \leq 0.05$ is considered significant.

Abbreviations: EDC, extensor digitorum communis; MCD, mean consecutive difference. 


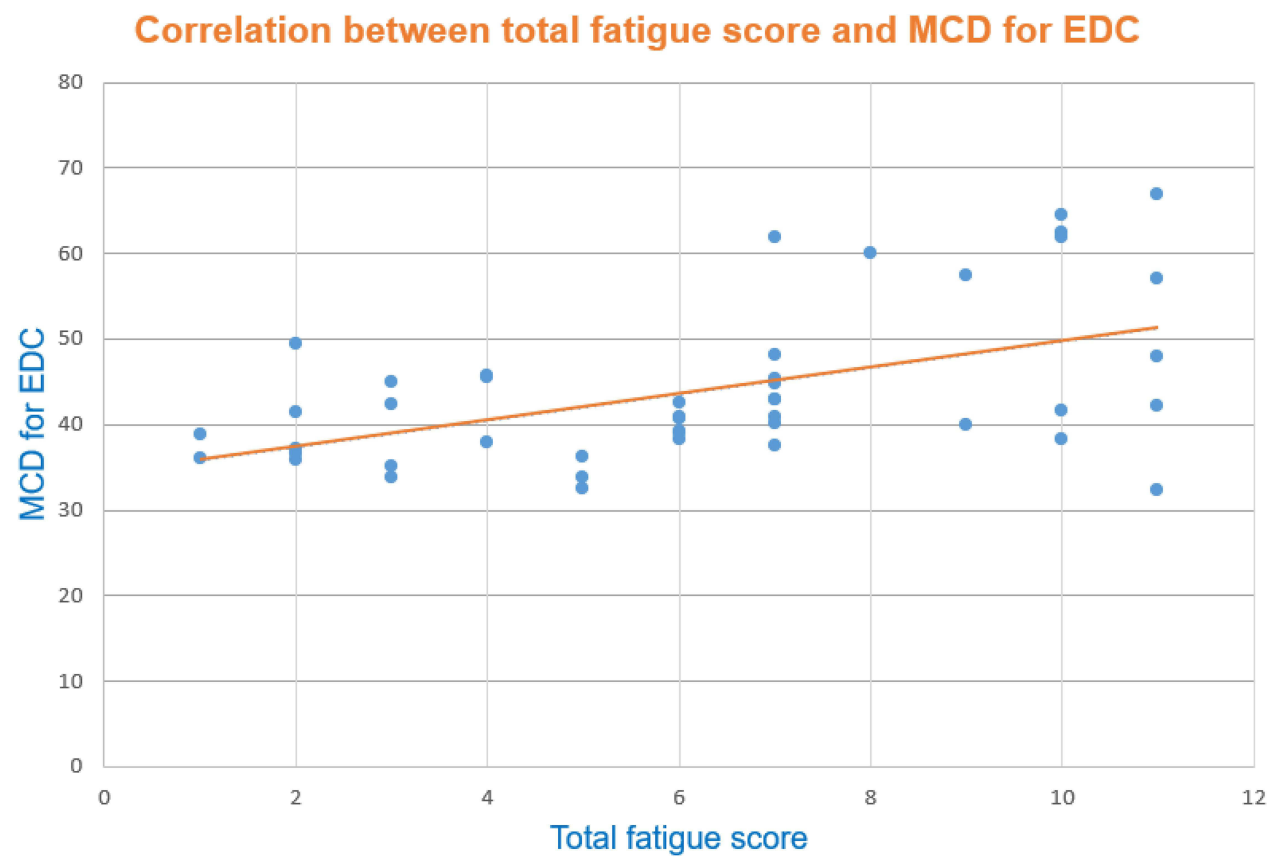

Figure I Correlation between total fatigue scores and MCD for EDC in patients with PIFS.

Abbreviations: EDC, extensor digitorum communis; MCD, mean consecutive difference.

The strength of our study is that it is the first to provide both clinical and neurophysiological assessment of fatigue in COVID-19 long-haulers. The main limitation is that we did not assess the levels of any circulating proinflammatory cytokines or markers of peripheral immunoactivation in our patients.

This study might pave the way for future research on the possible mechanisms underlying PIFS in COVID-19 longhaulers. Additionally, follow-up of such subjects to identify long-term outcomes is mandatory.

\section{Conclusion}

Higher ferritin levels and prolonged COVID-19 infection were found to be independent predictors of PIFS in COVID-19 long-haulers. Moreover, this study presents clear electrophysiological evidence of abnormalities in the peripheral portion of the motor unit in COVID-19 longhaulers with PIFS. Such abnormalities were demonstrated in the patients despite the fact that they did not have neuropathy or myopathy either clinically or electrophysiologically.

\section{Data Sharing Statement}

The data sets used and/or analyzed during the current study are available from the corresponding author on reasonable request.

\section{Ethics Approval and Patient Consent}

Written informed consent was obtained from all participants. Ethics approval for this study was obtained from the research-ethics committee of Beni-Suef University (FMBSUREC/03012021/Hussein). The study was performed in accordance with the Declaration of Helsinki.

\section{Author Contributions}

All authors made substantial contributions to conception and design, acquisition of data, or analysis and interpretation of data, took part in drafting the article or revising it critically for important intellectual content, agreed to submit to the current journal, gave final approval to the version to be published, and agree to be accountable for all aspects of the work.

\section{Funding}

The authors did not receive any funding for this work.

\section{Disclosure}

This work was not supported by any organization. The authors report no conflicts of interest for this work. 


\section{References}

1. Guan WJ, Ni ZY, Hu Y, et al. Clinical characteristics of coronavirus disease 2019 in China. $N$ Engl J Med. 2020;382(18):1708-1720. doi:10.1056/NEJMoa2002032

2. Wilson C. Concern coronavirus may trigger post-viral fatigue syndromes. New Scientist. 2020;246(3278):10-11.

3. Stormorken E, Jason LA, Kirkevold M. From good health to illness with post-infectious fatigue syndrome: a qualitative study of adults' experiences of the illness trajectory. BMC Fam Pract. 2017;18(1):49. doi:10.1186/s12875-017-0614-4

4. Bested AC, Marshall LM. Review of myalgic encephalomyelitis/ chronic fatigue syndrome: an evidence-based approach to diagnosis and management by clinicians. Rev Environ Health. 2015;30 (4):223-249. doi:10.1515/reveh-2015-0026

5. Nacul LC, Lacerda EM, Campion P, et al. The functional status and well being of people with myalgic encephalomyelitis/chronic fatigue syndrome and their carers. BMC Public Health. 2011;11:402. doi:10.1186/1471-2458-11-402

6. Kingdon CC, Bowman EW, Curran H, Nacul L, Lacerda EM. Functional status and well-being in people with myalgic encephalomyelitis/chronic fatigue syndrome compared with people with multiple sclerosis and healthy controls. Pharmacoecon Open. 2018;2 (4):381-392. doi:10.1007/s41669-018-0071-6

7. Falk Hvidberg M, Brinth LS, Olesen AV, Petersen KD, Ehlers L. The health-related quality of life for patients with myalgic encephalomyelitis/chronic fatigue syndrome (ME/CFS). PLoS One. 2015;10(7): e0132421. doi:10.1371/journal.pone.0132421

8. Lin JS, Resch SC, Brimmer DJ, et al. The economic impact of chronic fatigue syndrome in Georgia: direct and indirect costs. Cost Eff Resour Alloc. 2011;9(1):1. doi:10.1186/1478-7547-9-1

9. Curci C, Negrini F, Ferrillo M, et al. Functional outcome after inpatient rehabilitation in post-intensive care unit COVID-19 patients: findings and clinical implications from a real-practice retrospective study. Eur J Phys Rehabil Med. 2021.

10. Vitacca M, Carone M, Clini EM, et al. Joint statement on the role of respiratory rehabilitation in the COVID-19 crisis: the Italian position paper. Respiration. 2020;99(6):493-499. doi:10.1159/ 000508399

11. Andrenelli E, Negrini F, Patrini M, Lazzarini SG, Ceravolo MG. Rehabilitation and COVID-19: a rapid living systematic review by cochrane rehabilitation field updated as of December 31st, 2020 and synthesis of the scientific literature of 2020. Eur J Phys Rehabil Med. 2021. doi:10.23736/S1973-9087.20.06672-1

12. Ferraro F, Calafiore D, Dambruoso F, Guidarini S, de Sire A. COVID-19 related fatigue: which role for rehabilitation in post-COVID-19 patients? A case series. J Med Virol. 2020. doi:10.1002/jmv.26717

13. Halpin SJ, McIvor C, Whyatt G, et al. Postdischarge symptoms and rehabilitation needs in survivors of COVID-19 infection: a cross-sectional evaluation. J Med Virol. 2021;93(2):1013-1022. doi:10.1002/jmv.26368

14. Carruthers BM, van de Sande MI, De Meirleir KL, et al. Myalgic encephalomyelitis: international consensus criteria. J Intern Med. 2011;270(4):327-338. doi:10.1111/j.1365-2796.2011.02428.x

15. Goudsmit EM, Ho-Yen DO, Dancey CP. Learning to cope with chronic illness. Efficacy of a multi-component treatment for people with chronic fatigue syndrome. Patient Educ Couns. 2009;77 (2):231-236. doi:10.1016/j.pec.2009.05.015

16. Valls-Sole J. The utility of electrodiagnostic tests for the assessment of medically unexplained weakness and sensory deficit. Clin Neurophysiol Pract. 2016;1:2-8. doi:10.1016/j.cnp.2016.02.002

17. Jamal GA, Hansen S. Electrophysiological studies in the post-viral fatigue syndrome. J Neurol Neurosurg Psychiatry. 1985;48 (7):691-694. doi:10.1136/jnnp.48.7.691
18. Connolly S, Smith DG, Doyle D, Fowler CJ. Chronic fatigue: electromyographic and neuropathological evaluation. J Neurol. 1993;240 (7):435-438. doi:10.1007/BF00867358

19. Jamal GA, Hansen S. Post-viral fatigue syndrome: evidence for underlying organic disturbance in the muscle fibre. Eur Neurol. 1989;29(5):273-276. doi:10.1159/000116426

20. Committee on the Diagnostic Criteria for Myalgic Encephalomyelitis/Chronic Fatigue S, Board on the Health of Select $\mathrm{P}$, Institute of $\mathrm{M}$. The national academies collection: reports funded by national institutes of health. Beyond myalgic encephalomyelitis/ chronic fatigue syndrome: redefining an Illness. Washington, DC: National Academies Press (US) Copyright 2015 by the National Academy of Sciences; 2015.

21. World Health Organization. Clinical management of COVID-19: interim guidance, 27 May 2020. Geneva: World Health Organization; 2020.

22. American Psychiatric Association. Diagnostic and Statistical Manual of Mental Disorders; 2013.

23. Prokop M, van Everdingen W, van Rees Vellinga T, et al. CO-RADS: a categorical CT assessment scheme for patients suspected of having COVID-19-definition and evaluation. Radiology. 2020;296(2):E97E104. doi:10.1148/radiol.2020201473

24. Chalder T, Berelowitz G, Pawlikowska T, et al. Development of a fatigue scale. J Psychosom Res. 1993;37(2):147-153. doi:10.1016/ 0022-3999(93)90081-P

25. Lamb CJ, Rubin DI. Sensitivity and specificity of repetitive nerve stimulation with lower cutoffs for abnormal decrement in myasthenia gravis. Muscle Nerve. 2020;62(3):381-385. doi:10.1002/ mus. 26999

26. Sanders DB, Arimura K, Cui L, et al. Guidelines for single fiber EMG. Clin Neurophysiol. 2019;130(8):1417-1439. doi:10.1016/j. clinph.2019.04.005

27. Huang C, Wang Y, Li X, et al. Clinical features of patients infected with 2019 novel coronavirus in Wuhan, China. Lancet. 2020;395 (10223):497-506. doi:10.1016/S0140-6736(20)30183-5

28. Townsend L, Dyer AH. Persistent fatigue following SARS-CoV-2 infection is common and independent of severity of initial infection. PLoS One. 2020;15(11):e0240784. doi:10.1371/journal.pone.0240784

29. Simani L, Ramezani M. Prevalence and correlates of chronic fatigue syndrome and post-traumatic stress disorder after the outbreak of the COVID-19. Journal of Neurovirology. 2021;27(1):154-159. doi:10.1007/s13365-021-00949-1

30. Cortes Rivera M, Mastronardi C, Silva-Aldana CT, Arcos-Burgos M, Lidbury BA. Myalgic encephalomyelitis/chronic fatigue syndrome: a comprehensive review. Diagnostics. 2019;9(3):91. doi:10.3390/ diagnostics 9030091

31. Rasa S, Nora-Krukle Z, Henning N, et al. Chronic viral infections in myalgic encephalomyelitis/chronic fatigue syndrome (ME/CFS). J Transl Med. 2018;16(1):268.

32. Hickie I, Davenport T, Wakefield D, et al. Post-infective and chronic fatigue syndromes precipitated by viral and non-viral pathogens: prospective cohort study. BMJ. 2006;333(7568):575. doi:10.1136/ bmj.38933.585764.AE

33. Ocon AJ. Caught in the thickness of brain fog: exploring the cognitive symptoms of chronic fatigue syndrome. Front Physiol. 2013;4:63. doi:10.3389/fphys.2013.00063

34. Morris G, Maes M, Berk M, Puri BK. Myalgic encephalomyelitis or chronic fatigue syndrome: how could the illness develop? Metab Brain Dis. 2019;34(2):385-415.

35. McDonald CM. Clinical approach to the diagnostic evaluation of hereditary and acquired neuromuscular diseases. Phys Med Rehabil Clin N Am. 2012;23(3):495-563. doi:10.1016/j.pmr.2012.06.011

36. Gessel T, Rad N. Repetitive stimulation and neuromuscular junction disorders. In: Chu SK, Jayabalan P, Visco CJ editors. McLean EMG Guide. 2nd ed. New York: Springer Publishing Company; 2019:211-216. 
37. Kimura J. Electrodiagnosis in Diseases of Nerve and MusclePrinciples and Practice: Principles and Practice. Oxford University Press; 2013.

38. Juel VC. Single fiber electromyography. Handb Clin Neurol. 2019;160:303-310.

39. Mills KR. Specialised electromyography and nerve conduction studies. J Neurol Neurosurg Psychiatry. 2005;76(suppl 2):ii36. doi:10.1136/jnnp.2005.068981

40. Behan WM, More IA, Behan PO. Mitochondrial abnormalities in the postviral fatigue syndrome. Acta Neuropathol. 1991;83(1):61-65. doi:10.1007/BF00294431
41. Wood E, Hall KH, Tate W. Role of mitochondria, oxidative stress and the response to antioxidants in myalgic encephalomyelitis/chronic fatigue syndrome: a possible approach to SARS-CoV-2 'longhaulers'? Chronic Dis Transl Med. 2020. doi:10.1016/j. cdtm.2020.11.002

42. Missailidis D, Annesley SJ, Fisher PR. Pathological mechanisms underlying myalgic encephalomyelitis/chronic fatigue syndrome. Diagnostics. 2019;9(3):80. doi:10.3390/diagnostics9030080

\section{Publish your work in this journal}

Neuropsychiatric Disease and Treatment is an international, peerreviewed journal of clinical therapeutics and pharmacology focusing on concise rapid reporting of clinical or pre-clinical studies on a range of neuropsychiatric and neurological disorders. This journal is indexed on PubMed Central, the 'PsycINFO' database and CAS, and is the official journal of The International Neuropsychiatric Association (INA). The manuscript management system is completely online and includes a very quick and fair peer-review system, which is all easy to use. Visit http://www.dovepress.com/testimonials.php to read real quotes from published authors. 